\title{
Uji Daya Hasil S5 Jagung (Zea mays L.) Hibrida
}

Yield Trial Screening on S5 Hybrid Maize (Zea mays L.)

\author{
Nur Roslini ${ }^{1}$, Bakhtiar ${ }^{1}$, Siti Hafsah ${ }^{1}$ * \\ ${ }^{1}$ Program Studi Agroteknologi, Fakultas Pertanian, Universitas Syiah Kuala \\ *Corresponding author: sitihafsah@unsyiah.ac.id
}

\begin{abstract}
Abstrak. Penelitian ini bertujuan untuk menyeleksi tanaman jagung berdaya hasil tinggi. Penelitian ini dilaksanakan di PT Syngenta Seed Indonesia Kediri Field Station dusun Sukodono desa Kedungmalang kecamatan Papar kabupaten Kediri, Jawa Timur yang berlangsung pada Mei sampai Oktober 2019. Rancangan yang digunakan dalam penelitian ini adalah Rancangan Acak Kelompok (RAK) non faktorial dengan 24 genotipe uji, 4 genotipe pembanding (untuk uji daya hasil) dengan 2 ulangan. Pada uji daya hasil diperoleh 7 genotipe yaitu 18ID010144, 18ID010123, 18ID006020, 18ID010135, 18ID010125, 18 ID007419 dan 18ID010148 yang memiliki daya hasil tinggi diatas genotipe pembanding daya hasil tertinggi. 24 genotipe uji yaitu 18ID010125 memiliki daya hasil 14,12 ton ha-1 genotipe 18ID010123 memiliki daya hasil tertinggi 15,28 ton ha ${ }^{-1}$ dan genotipe 18ID010148 memiliki daya hasil 13,91 ton ha-1.
\end{abstract}

Kata kunci: Daya hasil, Jagung, genotype.

\begin{abstract}
This research aims to select maize are high yield. This research was conducted at PT Syngenta Seed Indonesia Kediri Field Station Sukodono in Sukodono sub-village, Kedungmalang village, Papar district, Kediri district, East Java, which took place from May to October 2019. The design used in this research was Non Factorial Randomized Block Design (RBD) with 24 test genotypes, 4 comparative genotypes (for yield trial) with 2 replications. The results showed that In yield trial was obtained 7 genotypes (18ID010144, 18ID010123, 18ID006020, 18ID010135, 18ID010125, 18 ID007419 dan 18ID010148) which have high yields above the highest comparative yield genotypes. There were 3 genotypes selected from 24 test genotypes consist 18ID010125 has yield 14,12 tons ha-1,genotype 18ID010123 has the highest yield 15,28 tons ha-1 and genotype 18ID010148 has yield 13,91 tons ha-1.
\end{abstract}

Keywords: yield, maize, genotype.

\section{PENDAHULUAN}

Jagung merupakan komoditas pangan yang memiliki potensi besar untuk kepentingan industri pangan, pakan, dan biofuel. Di negara maju, sari pati jagung diolah menjadi gula rendah kalori dan ampasnya diproses kembali untuk menghasilkan alkohol dan monosodium glutamat, dengan semakin berkembangnya industri pengolahan pangan di Indonesia maka kebutuhan akan konsumsi jagung di Indonesia terus meningkat. Hal ini didasarkan pada semakin meningkatnya tingkat konsumsi perkapita per tahun dan semakin meningkatnya jumlah penduduk Indonesia (Saragih et al., 2013).

Menurut BPS (2017), produksi nasional jagung tahun 2015 mencapai 19,61 juta ton sementara kebutuhan dalam negeri mencapai 25 juta ton, tahun 2016 produksi naik menjadi 23,57 ton dan pada tahun 2017 mencapai 27,95 ton. Walaupun produksinya meningkat, belum dapat memenuhi kebutuhan yang juga meningkat setiap tahunnya. Sedangkan menurut BPPP (2015) produktivitas jagung nasional tidak meningkat secara signifikan, karena di Indonesia sendiri produktivitas jagung terganggu dengan adanya OPT (Organisme Pengganggu Tanaman) seperti hama, penyakit dan gulma.

Salah satu penyakit penting pada tanaman jagung adalah bulai. Potensi hasil genotipe jagung tidak tercapai apabila tertular penyakit bulai (Hooda et al., 2012). Pada saat terjadi epidemik penyakit bulai di suatu daerah endemik, luas penularan dapat mencapai ribuan hektar. Penyakit bulai sudah menjadi penyakit endemik di beberapa daerah terutama di Pulau Jawa yaitu Jawa Timur (Kabupaten Kediri, Jombang, dan Blitar), Kalimantan Barat (Kabupaten Bengkayang) (Talanca, 2009). 
Langkah pertama yang dilakukan untuk perakitan genotipe dengan daya hasil tinggi yaitu dengan melakukan screening galur yang akan digunakan sebagai materi genetik yang merupakan salah satu proses dalam uji daya hasil pada tanaman jagung hibrida. Metode seleksi berulang dan skrining merupakan metode yang sangat efektif digunakan untuk memperbaiki peningkatan daya hasil. Seleksi berulang meliputi identifikasi dan intermating dari genotipe unggul dalam populasi untuk membentuk populasi baru dan ditingkatkan dari seleksi yang selanjutnya merupakan metode yang efesien untuk meningkatkan frekuensi gen yang diinginkan (Premalatha et al., 2012).

Berdasarkan uraian diatas, maka dilakukan penelitian untuk mendapatkan tanaman jagung yang berdaya hasil tinggi dengan metode pemuliaan tanaman.

\section{METODE PENELITIAN}

Penelitian ini telah dilaksanakan di PT Syngenta Seed Indonesia Kediri Field Station dusun Sukodono desa Kedungmalang kecamatan Papar kabupaten Kediri, Jawa Timur. Stasiun Riset Syngenta ini terletak pada ketinggian 60 mdpl ( $7^{\circ} 42^{\prime} 24.4^{\prime \prime} \mathrm{S}$ $112^{\circ} 06^{\prime} 52.3^{\prime \prime}$ E). Kegiatan ini akan berlangsung mulai dari Mei sampai dengan Oktober 2019.

\section{MATERI DAN METODE}

\section{Alat dan Bahan}

Alat-alat yang digunakan adalah traktor, sprayer, tugal, meteran kayu, pompa air, hand tally counter, EDC (Electronic Data Computer), gunting, grain moisture tester, timbangan digital, meteran, timbangan $100 \mathrm{~kg}$, wangkil, camera digital, papan label, alat tulis, laptop.

Bahan-bahan yang digunakan adalah Bahan yang digunakan dalam penelitian ini adalah 24 genotipe uji, dan 4 genotipe pembanding (untuk uji daya hasil). Genotipe uji terdiri dari 18ID010135, 18ID010125, 18ID010128, 19ID000861, 19ID000860, 18ID010144, 18ID010147, 18ID010148, 18ID010123, 18ID010141, 18ID010139, 18ID010154, 18ID010145, 18ID010143, 18ID010158, 18ID006020, 18ID010157, 18ID010151, 18ID010134, 18ID010118, 18ID007419, 19ID000695, 18ID010122 dan 17ID006285 . Genotipe pembanding meliputi 1 pembanding internal yaitu 19ALL111JL7_MM dan 3 pembanding eksternal (kompetitor) yaitu 19ALL111JLJ_MM, 19ALL111JLA_MM dan 19ALL111JLD_MM. Bahan lain yang digunakan yaitu jagung varietas Anoman, pupuk Urea, $\mathrm{KCl}$, SP-36, furadan (carbofuran), cruiser dan acrobat (insektisida dan fungisida untuk treatment benih), calaris (herbisida), dan matador (hama).

\section{Metode Penelitian}

Penelitian ini menggunakan Rancangan Acak Kelompok (RAK) non faktorial dengan 24 genotipe uji dan 4 genotipe pembanding (untuk uji daya hasil). Penelitian ini menggunakan 2 ulangan. Pada uji daya hasil terdapat 56 satuan percobaan dengan setiap satuan percobaan terdiri atas 100 tanaman. Data akan diolah menggunakan program Microsoft Excel.

Metode pengujian daya hasil yaitu benih diberikan perlakuan sebelum ditanam dengan menggunakan fungisida (acrobat dengan bahan aktif dimetomorf) dan insektisida (cruiser dengan bahan aktif untuk tiametoksam) yang bertujuan mencegah serangan fungi seperti bulai dan hama saat masa tumbuh. Fungisida dan insektisida akan melindungi benih hingga 20 hari setelah tanam. Tujuannya agar populasinya memenuhi standar. Kemudian genotipe uji dan pembanding yang telah diberikan perlakuan benih 
ditanam dengan 2 kali ulangan dengan 26 lubang tanam (1 lubang 2 benih). Setiap ulangan terdiri dari 4 baris. Jarak tanam yang digunakan yaitu 70 x $20 \mathrm{~cm}$ dengan panjang dalam 1 baris yaitu $5,2 \mathrm{~m}$. Setelah itu dilakukan pemeliharaan seperti penjarangan saat tanaman berumur 14-20 HST dengan tujuan agar hanya terdapat 1 tanaman dalam 1 luban atau dapat dilakukan secara bertahap pada saat 14, 25, 30 HST agar dapat mempertahankan jumlah populasi. Kemudian pemupukan dilakukan sebanyak 3 kali yaitu pada umur 7-10, 20-25 dan 40-45 HST. Pupuk yang diberikan yaitu NPK Phonska (15:15:15). Pemupukan dilakukan dengan cara ditugal. Pemupukan pertama diberikan urea dengan dosis sebanyak $350 \mathrm{~kg}$ ha-1, pemupukan kedua dengan dosis $250 \mathrm{~kg}$ urea ha-1 dan ketiga dengan dosis $250 \mathrm{~kg}$ urea ha-1. Serta pemeliharaan lainnya meliputi penyiraman, penyiangan gulma, pembumbunan dan pengendalian organisme pengganggu tanaman. Kemudian pemanenan dilakukan yaitu memanen benih dengan ciri-ciri kelobot mengering $95 \%$ berwarna kecoklatan tau bisa dilakukan dengan cara memipil biji jagung dan mengelupas bagian biji yang menempel di janggel (biji telah mengeras dan telah membentuk lapisan hitam (black layer) minimal 50\% disetiap barisan biji), batang dan daun sudah mengering serta berubah menjadi warna kecoklatan. Baris yang dipanen merupakan dua baris tengah dalam satu plot (4 baris).

Peubah yang diamati antara lain:

\section{Jumlah Tongkol Saat Panen}

Dihitung tongkol yang baik dan tongkol busuk (jika terdapat biji busuk lebih atau sama dengan 10 biji) per genotipe uji pada dua baris tengah tanaman.

\section{Berat Tongkol Tanpa Kelobot (kg)}

Ditimbang semua tongkol yang telah dikupas per genotipe uji pada dua baris tengah.

\section{Berat 5 Tongkol Tanpa Kelobot (g)}

Diambil 5 tongkol secara acak lalu dikupas kemudian ditimbang per genotipe uji.

\section{Berat 5 Tongkol Jagung pipil (g)}

Diambil 5 tongkol jagung per genotipe lalu timbang jagung yang telah dipipil .

\section{Kadar Air (\%)}

Pengukuran kadar air dilakukan dengan mengambil 5-10 tongkol secara acak pada saat panen kemudian dipipil lalu diukur kadar airnya dengan menggunakan grain mouisture tester.

\section{Rendemen Biji (\%)}

Dilakukan pada saat panen. Diambil 5-10 tongkol secara acak ditimbang kemudian dipipil lalu ditimbang lagi dan dihitung persentase rendemen dengan rumus sebagai berikut

$$
\text { Rendemen biji }=\frac{\text { Berat } 5 \text { tongkol jagung tanpa kelobot }}{\text { Berat } 5 \text { tongkol jagung pipil }} \times 100 \%
$$

\section{Penghitungan Potensi Hasil (ton ha ${ }^{-1}$ )}

Potensi Hasil dihitung dengan rumus : 
Potensi hasil $\left(\right.$ ton $\left.\mathrm{ha}^{-1}\right)=\frac{100-\text { Kadar air }}{100-15} \times$ Berat Tongkol $\times \frac{10.000 \mathrm{~m} 2}{\text { Luasan plot }} \times \frac{\text { Rendemen }}{100}$

Keterangan:

Kadar air

$=$ Persentase kadar air jagung yang dihitung dengan grain moiusture tester

15

= Konstanta kadar air

Luasan plot $\quad=$ Jarak tanam $\mathrm{x}$ jumlah ulangan $\mathrm{x}$ panjang petak $(0,7 \mathrm{~m} \times 2 \times 5,2 \mathrm{~m})$

Berat tongkol = Berat tongkol per genotipe uji pada dua baris tengah.

Rendemen Biji = Dihitung dengan cara mengambil 5 tongkol per genotipe kemudian ditimbang, lalu 5 tongkol tersebut dipipil dan kembali ditimbang (Sudaryono, 1998).

\section{Tipe Biji}

Tipe biji terdiri dari $1:$ flint (mutiara) , $2:$ semi flint (semi mutiara), 3 :semi dent (semi gigi kuda) dan 4 : dent (gigi kuda).

Tabel 1. Tipe Biji Jagung

\begin{tabular}{cl}
\hline Tipe Biji & \multicolumn{1}{c}{ Sifat-sifat } \\
\hline Dent (gigi kuda) & $\begin{array}{l}\text { Biji berbentuk gigi, pati yang keras menyelubungi pati yang } \\
\text { lunak sepanjang biji tetapi tidak sampai ke ujung. } \\
\text { Biji sangat keras, pati yang lunak sepenuhnya diselubungi } \\
\text { oleh pati yang keras, tahan terhadap serangan hama gudang }\end{array}$ \\
\hline
\end{tabular}

Sumber : IBPGR (1991)

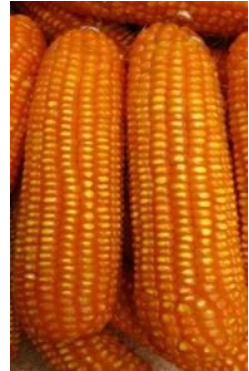

1

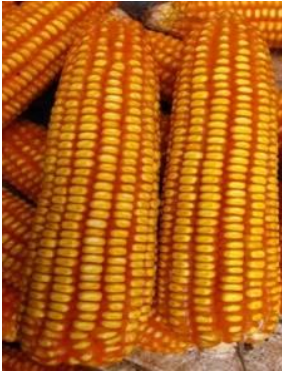

2

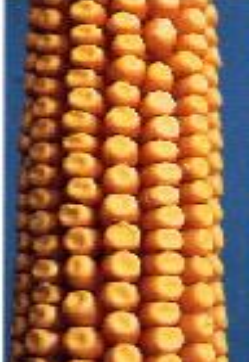

3

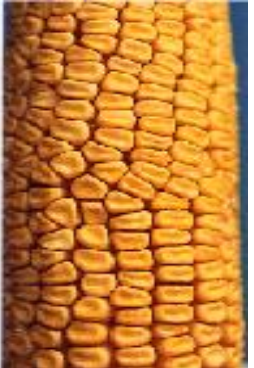

4

Gambar 1. Tipe biji

(Sumber : Syngenta Seed)

\section{Analisa Statistik}

Analisis data menggunakan analisis ragam yang dilanjutkan dengan uji BNT (Beda Nyata Terkecil) apabila ada nilai signifikasi antarperlakuan pada taraf 5\%.

\section{HASIL DAN PEMBAHASAN}

\section{Uji Daya Hasil Jagung Hibrida S5}

Selain mendapatkan ketahanan terhadap suatu penyakit faktor lain yang membuat suatu tanaman bernilai tinggi yaitu potensi hasilnya. Pada penelitian ini juga dilakukan uji daya hasil terhadap genotipe-genotipe uji yang diuji pada ketahanan penyakit. 
Hasil Uji F menunjukkan bahwa parameter yang memiliki pengaruh sangat nyata pada tiap genotipe yaitu berat tongkol dan potensi hasil serta tidak berpengaruh nyata terhadap kadar air dan jumlah tongkol.

Tabel 2. Rata-rata Jumlah Tongkol, Berat Tongkol dan Kadar Air saat Panen Genotipe Uji dan Pembanding

\begin{tabular}{clclc}
\hline No & Genotipe & Jumlah Tongkol & Berat Tongkol & Kadar Air saat Panen (\%) \\
\hline 1 & 18ID010135 & 50 & $14,81 \mathrm{~g}-\mathrm{j}$ & 26,15 \\
2 & 18ID010125 & 50 & $14,42 \mathrm{e}-\mathrm{j}$ & 25,80 \\
3 & 18ID010128 & 53 & $13,63 \mathrm{~b}-\mathrm{j}$ & 25,60 \\
4 & 19ID000861 & 53 & $13,96 \mathrm{~d}-\mathrm{j}$ & 26,25 \\
5 & 19ID000860 & 51 & $13,62 \mathrm{~b}-\mathrm{j}$ & 25,30 \\
6 & 18ID010144 & 49 & $16,45 \mathrm{j}$ & 26,60 \\
7 & 18ID010147 & 47 & $11,60 \mathrm{ab}$ & 25,90 \\
8 & 18ID010148 & 63 & $14,55 \mathrm{f}-\mathrm{j}$ & 25,15 \\
9 & 18ID010123 & 54 & $15,48 \mathrm{ij}$ & 25,40 \\
10 & 18ID010141 & 46 & $14,41 \mathrm{e}-\mathrm{j}$ & 26,90 \\
11 & 18ID010139 & 60 & $13,1 \mathrm{c}-\mathrm{j}$ & 24,35 \\
12 & 18ID010154 & 52 & $12,57 \mathrm{a}-\mathrm{g}$ & 25,05 \\
13 & 18ID010145 & 42 & $12,10 \mathrm{a}-\mathrm{d}$ & 25,30 \\
14 & 18ID010143 & 45 & $11,43 \mathrm{a}$ & 25,40 \\
15 & 18ID010158 & 50 & $13,68 \mathrm{c}-\mathrm{j}$ & 24,80 \\
16 & 18ID006020 & 48 & $15,31 \mathrm{hij}$ & 25,95 \\
17 & 18ID010157 & 49 & $13,17 \mathrm{a}-\mathrm{h}$ & 26,10 \\
18 & 18ID010151 & 55 & $13,27 \mathrm{a}-\mathrm{i}$ & 26,00 \\
19 & 18ID010134 & 50 & $13,31 \mathrm{a}-\mathrm{i}$ & 24,80 \\
20 & 18ID010118 & 49 & $12,09 \mathrm{a}-\mathrm{d}$ & 25,20 \\
21 & 18ID007419 & 62 & $14,52 \mathrm{e}-\mathrm{j}$ & 24,95 \\
22 & 19ID000695 & 43 & $13,13 \mathrm{a}-\mathrm{h}$ & 25,40 \\
23 & 18ID010122 & 46 & $12,51 \mathrm{a}-\mathrm{f}$ & 24,95 \\
24 & 17ID006285 & 53 & $12,45 \mathrm{a}-\mathrm{e}$ & 26,15 \\
25 & 19ALL111JL7_MM & 54 & $14,25 \mathrm{e}-\mathrm{j}$ & 26,40 \\
26 & 19ALL111JLD_MM & 47 & $11,67 \mathrm{abc}$ & 26,40 \\
27 & 19ALL111JLJ_MM & 49 & $12,78 \mathrm{a}-\mathrm{h}$ & - \\
28 & 19ALL111JLA_MM & 46 & $11,85 \mathrm{a}-\mathrm{d}$ & $\mathbf{2 , 0 5}$ \\
\hline & BNTT,05 & - & & 25 \\
\hline
\end{tabular}

Keterangan : Angka yang diikuti oleh huruf yang sama dalam kolom yang sama tidak berbeda nyata pada taraf $5 \%(0,05)$

Tabel 2 pada peubah jumlah tongkol dan kadar air menunjukkan bahwa genotipe uji belum memperlihatkan perbedaan yang signifikan terhadap jumlah tongkol. Hal ini diduga karena rata-rata jumlah tongkol per tanaman yaitu dua sehingga perbedaan jumlah tongkol pada masing-masing genotipe disebabkan karena banyak atau tidaknya jumlah tanaman yang tumbuh. Genotipe yang memiliki jumlah tongkol terbanyak yaitu terdapat pada genotipe 18ID010148. Hal ini diduga karena genotipe 18ID010148 memiliki jumlah tanaman yang tumbuh lebih banyak sehingga mendukung banyaknya jumlah tongkol. Genotipe yang memiliki kadar air dengan nilai tertinggi terdapat pada genotipe 18ID010141 yaitu sebesar 26,90\% akan tetapi genotipe uji yang terbaik yaitu genotipe 19ALL111JLJ_MM dengan memiliki kadar air terendah yaitu 23,45\% karena genotipe dengan kadar air terendah merupakan genotipe terbaik. Hal ini terjadi karena semakin rendah kadar air suatu genotipe maka semakin baik daya simpannya.

Peubah berat tongkol menunjukkan bahwa genotipe uji memberikan pengaruh pada berat tongkol. Genotipe yang memiliki berat tongkol terberat terdapat pada genotipe 18ID010144 yaitu $16,45 \mathrm{~kg}$ yang berbeda nyata dengan dengan genotipe pembanding 19ALL111JLD_MM, 19ALL111JLJ_MM dan 19ALL111JLA_MM, tetapi tidak berbeda nyata dengan genotipe pembanding 19ALL111JL7_MM. Hal ini diduga 
karena genotipe 18ID010144 memiliki jumlah tongkol yang banyak dan juga memiliki ukuran tongkol yang besar ataupun medium. Genotipe 18ID010144 memiliki potensi untuk dikembangkan dalam dunia industri karena memiliki bobot tongkol yang terbaik. Menurut Wulandari dan Sugiharto (2017), galur yang memiliki bobot tongkol dan kedalaman biji terbaik cocok dikembangkan dalam industri.

Tabel 3. Rata-rata Berat 5 Tongkol Tanpa Kelobot, Berat 5 Tongkol Pipilan, Rendemen Biji dan Potensi Hasil Genotipe Uji dan Pembanding

\begin{tabular}{|c|c|c|c|c|c|}
\hline No & Genotipe & $\begin{array}{c}\text { Berat } 5 \\
\text { tongkol tanpa } \\
\text { kelobot (kg) }\end{array}$ & $\begin{array}{c}\text { Berat } 5 \\
\text { Tongkol } \\
\text { Pipilan (kg) }\end{array}$ & $\begin{array}{c}\text { Rendemen } \\
\text { Biji (\%) }\end{array}$ & $\begin{array}{l}\text { Potensi Hasil } \\
\quad\left(\text { ton } \mathbf{h a}^{-1}\right)\end{array}$ \\
\hline 1 & 18ID010135 & 1,83 & $1,51 \mathrm{~g}$ & $82,36 \mathrm{f}-\mathrm{i}$ & $14,56 \mathrm{f}-\mathrm{i}$ \\
\hline 2 & 18ID010125 & 1,66 & $1,35 \mathrm{a}-\mathrm{f}$ & $81,64 d-i$ & $14,12 \mathrm{e}-\mathrm{i}$ \\
\hline 3 & 18ID010128 & 1,63 & $1,28 \mathrm{a}-\mathrm{e}$ & $78,65 \mathrm{a}$ & $12,89 \mathrm{a}-\mathrm{g}$ \\
\hline 4 & 19ID000861 & 1,70 & $1,38 \mathrm{~b}-\mathrm{f}$ & $80,92 \mathrm{a}-\mathrm{i}$ & $13,47 \mathrm{~b}-\mathrm{i}$ \\
\hline 5 & 19ID000860 & 1,54 & 1,26 a-d & $81,48 \mathrm{c}-\mathrm{i}$ & $13,39 \mathrm{~b}-\mathrm{i}$ \\
\hline 6 & 18ID010144 & 1,76 & $1,42 \mathrm{def}$ & 80,46 a-g & $15,69 \mathrm{i}$ \\
\hline 7 & 18ID010147 & 1,71 & 1,43 ef & $83,72 \mathrm{i}$ & $11,65 \mathrm{abc}$ \\
\hline 8 & 18ID010148 & 1,55 & $1,22 \mathrm{ab}$ & $79,05 \mathrm{ab}$ & $13,91 \mathrm{~d}-\mathrm{i}$ \\
\hline 9 & 18ID010123 & 1,48 & $1,21 \mathrm{a}$ & $81,92 \mathrm{e}-\mathrm{i}$ & $15,28 \mathrm{hi}$ \\
\hline 10 & 18ID010141 & 1,76 & $1,42 \mathrm{def}$ & 80,89 a-h & $13,80 \mathrm{~d}-\mathrm{i}$ \\
\hline 11 & 18ID010139 & 1,52 & $1,24 \mathrm{abc}$ & $81,53 \mathrm{c}-\mathrm{i}$ & $13,67 \mathrm{c}-\mathrm{i}$ \\
\hline 12 & 18ID010154 & 1,54 & $1,26 a-d$ & $81,44 c-i$ & 12,40 a-e \\
\hline 13 & 18ID010145 & 1,69 & $1,34 \mathrm{a}-\mathrm{f}$ & $79,28 \mathrm{abc}$ & $11,58 \mathrm{abc}$ \\
\hline 14 & 18ID010143 & 1,58 & $1,26 \mathrm{a}-\mathrm{d}$ & 79,91 a-e & $10,99 \mathrm{a}$ \\
\hline 15 & 18ID010158 & 1,63 & $1,36 \mathrm{~b}-\mathrm{f}$ & $82,99 \mathrm{hi}$ & $13,80 \mathrm{~d}-\mathrm{i}$ \\
\hline 16 & 18ID006020 & 1,59 & 1,28 a-e & 80,98 b-i & 14,84 ghi \\
\hline 17 & 18ID010157 & 1,68 & $1,40 \mathrm{c}-\mathrm{f}$ & 83,12 hi & $13,07 \mathrm{a}-\mathrm{h}$ \\
\hline 18 & 18ID010151 & 1,78 & $1,45 \mathrm{ef}$ & $81,83 \mathrm{e}-\mathrm{i}$ & 12,98 a-h \\
\hline 19 & 18ID010134 & 1,65 & $1,34 \mathrm{a}-\mathrm{f}$ & $81,28 \mathrm{~b}-\mathrm{i}$ & $13,14 \mathrm{~b}-\mathrm{h}$ \\
\hline 20 & 18ID010118 & 1,66 & $1,35 \mathrm{a}-\mathrm{f}$ & $81,54 \mathrm{c}-\mathrm{i}$ & $11,92 \mathrm{a}-\mathrm{d}$ \\
\hline 21 & 18ID007419 & 1,73 & $1,37 \mathrm{a}-\mathrm{f}$ & 79,35 a-d & $13,96 \mathrm{~d}-\mathrm{i}$ \\
\hline 22 & 19ID000695 & 1,67 & $1,37 \mathrm{a}-\mathrm{f}$ & 82,56 ghi & $13,07 \mathrm{a}-\mathrm{h}$ \\
\hline 23 & 18ID010122 & 1,48 & $1,21 \mathrm{a}$ & $81,74 \mathrm{e}-\mathrm{i}$ & 12,40 a-e \\
\hline 24 & 17ID006285 & 1,61 & $1,33 \mathrm{a}-\mathrm{f}$ & $82,71 \mathrm{ghi}$ & 12,29 a-e \\
\hline 25 & 19ALL111JL7_MM & 1,67 & $1,36 \mathrm{a}-\mathrm{f}$ & $81,72 \mathrm{e}-\mathrm{i}$ & $13,85 \mathrm{~d}-\mathrm{i}$ \\
\hline 26 & 19ALL111JLD_MM & 1,62 & $1,34 \mathrm{a}-\mathrm{f}$ & $82,86 \mathrm{hi}$ & $11,50 \mathrm{ab}$ \\
\hline 27 & 19ALL111JLJ_MM & 1,67 & $1,34 \mathrm{a}-\mathrm{f}$ & $80,23 \mathrm{a}-\mathrm{f}$ & $12,67 \mathrm{a}-\mathrm{f}$ \\
\hline \multirow[t]{2}{*}{28} & 19ALL111JLA_MM & 1,72 & $1,40 \mathrm{c}-\mathrm{f}$ & $81,66 \mathrm{~d}-\mathrm{i}$ & $11,66 \mathrm{abc}$ \\
\hline & BNT $_{0,05}$ & - & 0,16 & 2,32 & 2,1 \\
\hline
\end{tabular}

Keterangan : Angka yang diikuti oleh huruf yang sama dalam kolom yang sama tidak berbeda nyata pada taraf $5 \%(0,05)$

Hasil penelitian pada Tabel 3 menunjukkan bahwa genotipe tidak memberikan perbedaan yang signifikan pada berat 5 tongkol tanpa kelobot. Genotipe yang memiliki berat 5 tongkol tanpa kelobot terbanyak terdapat pada genotipe 18ID010135 yaitu sebesar $1,83 \mathrm{~kg}$. Hal ini terjadi karena genotipe 18ID010135 memiliki tipe tongkol medium sampai besar, tetapi tidak memiliki jumlah tongkol yang banyak sehingga genotipe ini tidak memiliki nilai berat tongkol tertinggi.

Tabel 3 menunjukkan genotipe memberikan pengaruh terhadap peubah berat 5 tongkol pipilan. Berat 5 tongkol pipilan dengan nilai tertinggi terdapat pada genotipe 18ID010135 yaitu 1,51 kg yang berbeda nyata dengan genotipe pembanding 19ALL111JLJ_MM dan 19ALL111JLD_MM, tetapi tidak berbeda nyata dengan 19ALL111JL7_MM dan 19ALL111JLA_MM. Hal ini diduga karena genotipe 18ID010135 memiliki berat 5 tongkol tanpa kelobot dengan nilai tertinggi dari genotipe 
lainnya dan diduga memiliki kedalaman biji jagung yang dalam sehingga memiliki berat tongkol pipilan dengan nilai tertinggi.

Pada peubah rendemen biji Tabel 3 menunjukkan bahwa genotipe memberikan pengaruh terhadap rendemen biji tanaman jagung. Genotipe yang memiliki nilai rendemen biji tertinggi terdapat pada genotipe 18ID010147 yaitu sebesar 83,72\% yang berbeda nyata dengan genotipe pembanding 19ALL111JLJ_MM, tetapi tidak berbeda nyata dengan genotipe pembanding 19ALL111JL7_MM, 19ALL111JLD_MM dan 19ALL111JLA_MM. Genotipe 18ID010147 diduga memiliki diameter tongkol yang lebih besar dan diamater janggel lebih kecil sehingga memiliki nilai rendemen biji yang tinggi. Pendugaan ini sejalan dengan Robi'in (2009) yang menyatakan bahwa rendemen biji suatu varietas akan tinggi apabila memiliki diameter janggel yang lebih kecil dan diameter tongkol yang lebih besar pada suatu varietas

Pada peubah potensi hasil genotipe uji memberikan pengaruh. Potensi hasil tertinggi terdapat pada genotipe 18ID010144 yang berbeda nyata dengan genotipe pembanding 19ALL111JLJ_MM, 19ALL111JLA_MM dan 19ALL111JLD_MM, tetapi tidak berbeda nyata dengan genotipe pembanding hasil produksi tertinggi yaitu 19ALL111JL7_MM. Adanya perbedaan potensi hasil dipengaruhi oleh masing-masing genetik dari setiap genotipe dan lingkungan. Genotipe 18ID010144 memiliki potensi hasil yang tinggi dikarenakan genotipe ini memiliki jumlah tongkol yang cukup banyak, ukuran tongkol yang besar dan nilai berat tongkol yang tinggi. Hal ini sesuai dengan penelitian Wulandari dan Sugiharto (2017) yang menyatakan bahwa potensi hasil dipengaruhi oleh tinggi tanaman, jumlah tongkol per tanaman, berat tongkol tanpa kelobot, ukuran tongkol dan panjang tongkol. Pendugaan ini juga diperkuat oleh Fitriyani et al. (2019) yang menyatakan bahwa karakter ukuran tongkol yang panjang, diameter tongkol yang besar, jumlah baris biji yang banyak, didukung oleh ukuran bobot biji yang besar akan memberikan dampak terhadap potensi hasil suatu galur atau varietas yang lebih besar dibanding dengan galur atau varietas lain.

Data statistika menunjukkan bahwa genotipe 18ID010144 tidak berbeda nyata dengan genotipe pembanding daya hasil tertinggi (19ALL111JL7_MM) tetapi dilapangan perbedaan potensi hasil mencapai 1,85 ton $^{-1}$, sehingga genotipe ini bisa menjadi salah satu kandidat calon tetua untuk memperbaiki potensi hasil tanaman jagung.

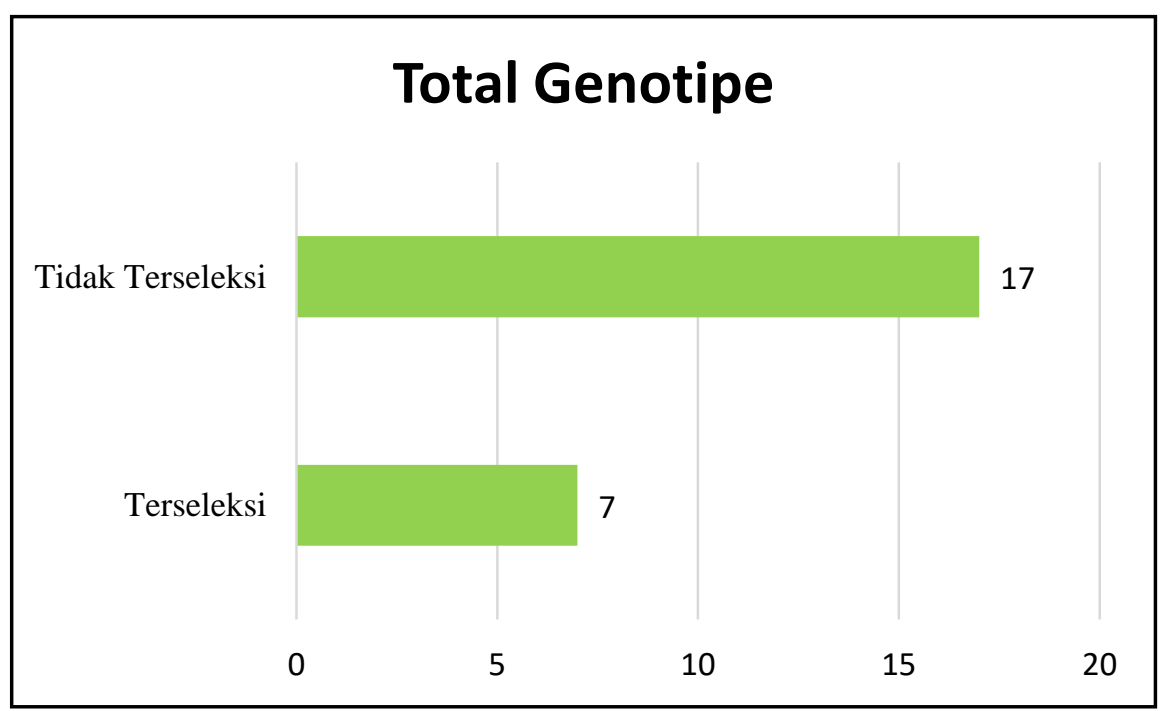

Gambar 2. Total Genotipe Uji yang Terpilih dan Tidak Terpilih Berdasarkan Potensi Hasil pada Uji Daya Hasil 
Gambar 2 menunjukkan bahwa genotipe yang tepilih pada uji daya hasil yaitu 7 genotipe uji. Genotipe yang terpilih merupakan genotipe yang memiliki potensi hasil diatas potensi hasil genotipe pembanding (19ALL111JL7_MM). Berdasarkan Tabel 1 genotipe tersebut terdiri atas 18ID010144 (15,69 ton ha $\left.{ }^{-1}\right), 18 \mathrm{ID} 010123\left(15,28\right.$ ton ha $\left.{ }^{-1}\right)$, $18 I D 006020\left(14,84\right.$ ton $\left.\mathrm{ha}^{-1}\right), 18 \mathrm{ID} 010135$ (14,56 ton ha $\left.{ }^{-1}\right), 18 \mathrm{ID} 010125$ (14,12 ton ha$\left.{ }^{1}\right), 18 \mathrm{ID} 007419\left(13,96\right.$ ton ha $\left.^{-1}\right)$ dan 18ID010148 (13,91 ton ha $\left.{ }^{-1}\right)$. Genotipe yang tidak terpilih pada uji daya hasil sebanyak 17. Genotipe yang tidak terpilih merupakan genotipe yang memiliki potensi hasil dibawah genotipe pembanding.

\section{Tipe Biji}

Hasil penelitian menunjukkan bahwa masing-masing genotipe memiliki perbedaan dalam tipe dan warna biji. Pada varietas pembanding 19ALL111JLA_MM, 19ALL111JLD_MM dan 19ALL111JL7_MM memiliki tipe biji semi flint (semi mutiara), sedangkan 19ALL111JLJ_MM memiliki tipe biji flint (mutiara). Genotipe uji yang memiliki tipe biji flint terdapat hanya pada genotipe 18ID010148. Genotipe yang memiliki tipe biji antara semi flint dan semi dent terdapat pada genotipe 18ID010154, 18ID010139, 18ID006020, 18ID010157, 18ID010147, 18ID010151 dan 18ID010122 serta genotipe yang memiliki tipe biji semi flint terdapat pada genotipe lainnya. Tipe biji dipengaruhi oleh genetik dari tetuanya, maka dari itu masing-masing genotipe uji memiliki tipe biji yang berbeda-beda.

Genotipe yang terpilih berdasarkan uji daya hasil yaitu 7 genotipe, namun yang lanjut untuk masuk ke tahap selanjutnya yaitu hanya 3 genotipe. Genotipe yang terpilih tersebut memiliki kelebihan dan kekurangan yaitu sebagai berikut :

\section{Hibrida 18ID010123}

Memiliki kelebihan yaitu potensi hasil yang tinggi dengan beda potensi hasil 1,10 diatas cek pembanding 1. Sedangkan kekurangannya yaitu tongkolnya cenderung memiliki ukuran medium dan Infeksi serangan bulai sebesar $71 \%$, atau bisa dikatakan dapat pecah ketahanannya sewaktu-waktu.

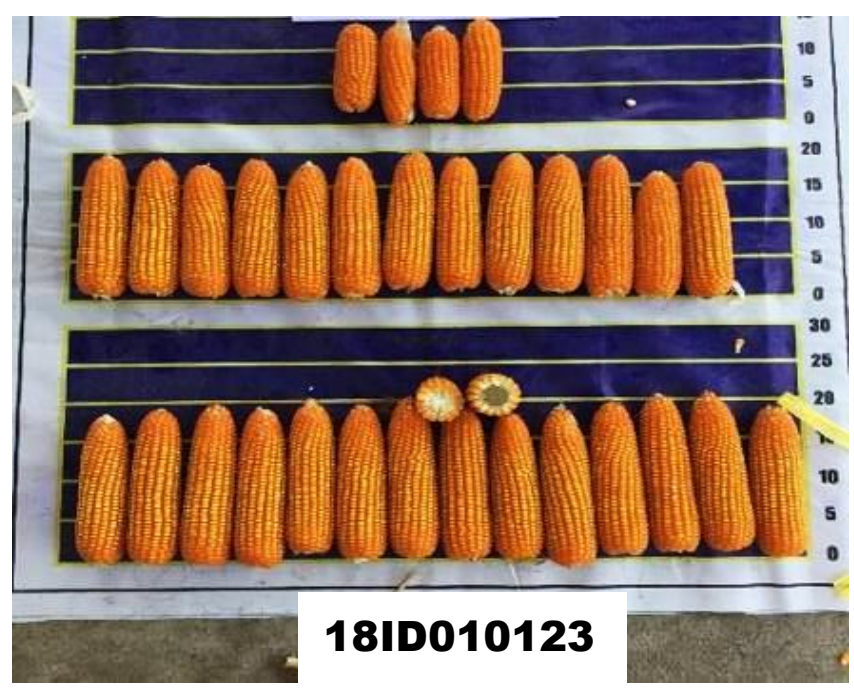




\section{Hibrida 18ID010125}

Memiliki kelebihannya yaitu tongkol jagung yang besar. Sedangkan kekurangannya yaitu ketahanan terhadap bulai dibawah cek pembanding bulai yaitu dengan infeksi serangan sebesar 54\%.

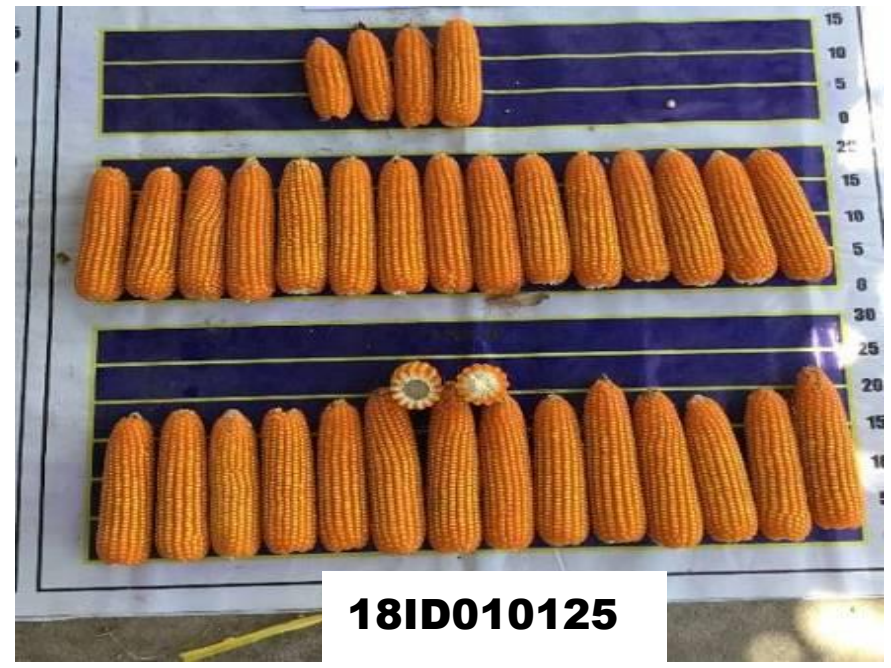

\section{Hibrida 18ID010148}

Memiliki kelebihan pada warna biji yang disukai petani yaitu jingga. Sedangkan kekurangannya yaitu tongkol memiliki potensi bogang dan memiliki infeksi serangan bulai sebesar $69 \%$.

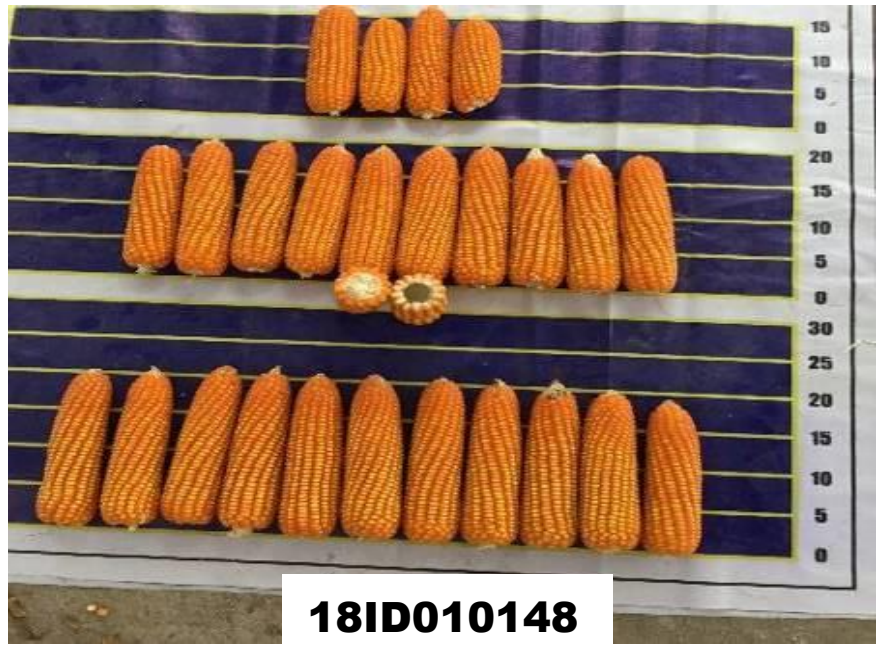

\section{KESIMPULAN DAN SARAN}

Pada uji daya hasil diperoleh 7 genotipe yaitu 18ID010144, 18ID010123, 18ID006020, 18ID010135, 18ID010125, 18ID007419 dan 18ID010148 yang memiliki daya hasil tinggi diatas genotipe pembanding daya hasil tertinggi. Genotipe yang memiliki daya hasil maksimal atau tertinggi yaitu terdapat pada genotipe 18ID010144 sebesar 15,69 ton $\mathrm{ha}^{-1}$.

Genotipe yang lanjut ke tahap selanjutnya diseleksi dengan membandingkan persentase ketahanan penyakit dan daya hasil, maka ada 3 genotipe yang terpilih dari 24 
genotipe uji yaitu 18ID010125 memiliki daya hasil 14,12 ton ha $^{-1}$, genotipe 18ID010123 memiliki daya hasil 15,28 ton $\mathrm{ha}^{-1}$ dan genotipe 18 ID010148 memiliki daya hasil 13,91 ton $\mathrm{ha}^{-1}$.

\section{DAFTAR PUSTAKA}

Badan Pengkajian dan Pengembangan Kebijakan Perdagangan. 2015. Potret Jagung Indonesia: Menuju Swasembada Tahun 2017. http://bppp.kemendag.go.id/. [Diakses 19 April 2018].

Badan Pusat Statistik. 2017. Data Produksi Jagung Manis Indonesia Tahun 2015-2016. Jakarta.

Fitriyani, D., J. Kartahadimaja dan N.A. Hakim. 2019. Uji daya hasil pendahuluan lima galur jagung (Zea mays L.) hibrida silang tunggal rakitan Politeknik Negeri Lampung. J. Penelitian Pertanian Terapan. 17(3): 89-94.

Hooda, K.S., V. Singh, T.A.S. Setty, S.S. Sharma, V. Parnidharan, R.N. Bunker dan J. Kaul. 2012. Screening of elite maize lines for resistance against downy mildews. J. Maize. 1(2):110-112.

[IBPGR] International Board for Plant Genetic Resource. 1991. Descriptors for Maize. IBPGR, Roma.

Premalatha, N., K.M. Sundaran dan S. Arumugachamy. Screening and source of resistance to downy mildew (Peronosclerospora sorghi) in Maize (Zea mays L.). E-Journal Plant Breeding. 3(2): 788-793.

Robi'in. 2009. Teknik Pengujian Daya Hasil Jagung Bersari Bebas (Komposit)di Lokasi Prima Tani Kabupaten Probolinggo Jawa Timur. Buletin Teknik Pertanian. 14(2) $: 45-49$.

Saragih, D., H. Hamim dan N. Nurmauli. 2013. Pengaruh dosis dan waktu aplikasi pupuk urea dalam meningkatkan pertumbuhan dan hasil jagung (Zea mays L.) Pioneer 27. J. Agrotek Tropika. 1(1):50-54.

Sudaryono. 1998. Teknologi Produksi Jagung. Prosiding Seminar dan Lokakarya Nasional Jagung. Balai penelitian Tanaman Jagung dan Serealia, Ujung Pandang.

Talanca, A.H. 2009. Status Penyakit Bulai Pada Tanaman Jagung dan Pengendaliannya. Laporan Hasil Penelitian Balitsereal. Maros, Jawa Timur.

Wulandari, D.R. dan A.N. Sugiharto. 2017. Uji daya hasil pendahuluan beberapa galur jagung manis (Zea mays L. sacchaarata). J. Produksi Tanaman. 5(12): 19982007. 